dangers in this case were largely due to the very extensive origin of the growth, there being no welldefined pedicle, and consequently a very extensive ligation of tissue. It is true that this should not ordinarily produce a disastrous result, and I have the report of a case in which a rapidly growing ovarian tumor-only having been noticed by the patient six weeks-in which the operation was prolonged from numerous adhesions and the bursting of a cyst, the pedicle broad, which was ligated in sections with shoemaker's thread, and yet the patient did well. I think that the very profound and almost immediately fatal shock, together with bad toleration of the anæsthetics used, the effects of which persisted to the last, were the chief factors in the fatal termination of this case.

That an operation was justifiable there can be no doubt, as the patient repeatedly solicited it, and no other procedure could have with any certainty given a hope of prolonged life. And I may say the above opinions are fully concurred in by Drs. Welch and Gray, to whom Dr. Weems and myself are under many obligations for the valuable assistance rendered in the case.

\section{PERMANGANATE OF POTASH IN THE TREATMENT OF ECZEMA. ${ }^{1}$}

BY W. B. LAWRENCE, M.D., OF BATESVille, ARK.

In the Medical and Surgical Reporter, of July x I, $\mathbf{8 8 5}$, I read the following in regard to "Permanganate Potash Baths:"

"In June, I879, a well-developed child, of two years of age, was brought to Dr. Hüllman (Archiv. für Kinderheilk, Band vi, Heft 3), covered with eczema and impetigo. He had been sent from Berlin to Halle to try the baths there, but after three weeks he was worse instead of better. He was therefore prescribed an immersion-bath of permanganate of potash of the strength of fifteen grains to a pail of water, the child to remain in it until the fluid began to turn brownish. Fourteen days afterwards he was cured. Since then Dr. Hüllman has used the remedy both in adults and in children, and mostly with good effect. He has not confined its use to eczema, but has also employed it in prurigo, intertrigo, and the desquamating stage of measles, scarlatina and varicella. When the skin is much covered with scales or scabs it should first be well brushed with soap and water. For convenience of use he keeps a concentrated solution made of hot water."

At the time I saw this short article I had under treatment a very stubborn case of chronic eczema. I say chronic, because it was of almost three months' duration. It covered nearly the entire surface of all the fingers on one hand. The patient, a married lady, and in perfect health otherwise, had a hereditary predisposition to eczema. I had about exhausted all of the remedies generally used in this disease, so far as my knowledge goes. I had prescribed

1 Read before the State Medical Society of Arkansas, Eleventh Annual Session, Little Rock, April 28 and $29,1886$. the tar ointment, citrine ointment, and others, besides nitric acid, with which I have cured similar cases heretofore; and in addition to the local remedies the patient had been taking liq. pot. arsenitis, 6 to 8 drops after each meal.

Under this treatment my patient's malady did not improve in the least, but gradually grew worse. Anxious to try anything reasonable, and remembering the good effects claimed for this drug in the treatment of some forms of foul ulcers, I ordered the following:

R. Potassii permanganas............... grs. $x$

Aquæ............................... ${ }_{3} \mathrm{j}$

The solution to be applied freely daily with a camel's-hair brush. Under this treatment the disease entirely disappeared in about twelve days. Of course the new skin remained somewhat tender for some days. She left off the arsenic when she began the potash.

I think it was in September that I treated another case of eczema. The patient was a young lady, and in other respects her health was perfect; no hereditary tendency, so far as I was able to find out, of any form of skin disease. The disease was on the face, in the region of the mouth, in fact almost covering both lips. She had used iodine and carbolized cosmoline, but with no good effect. I ordered

$$
\text { Pot. permangs.................... grs. } \mathbf{v}
$$$$
\text { Aquæ..................................... }
$$

The solution to be applied freely daily with a camel'shair brush. Under this treatment the patient was cured within fifteen days.

In December I saw another case. The patient, a child one year of age, a male, well developed, and with the exception of this skin disease in perfect health. The disease was situated in the external ear and extended to some little extent down on the jaw. I ordered same formula as last, to be applied in the same manner as in the two previous cases, and within a week's time the disease had entirely disappeared.

\section{NARCEINE IN WHOOPING-COUGH.' BY LLEWELLYN ELIOT, M.D., OF WASHINGTON, D, $\mathrm{C}$.}

Whooping-cough is one of the most distressing diseases of childhood, although it has been observed in adults. It seldom occurs before the sixth month of life, nor is it frequent after the eighth year. Second attacks are exceedingly rare. Barthez and Rilliet mention a case occurring on the day after birth, the mother having had the disease four weeks previously. Bouchet mentions a case infected on the second day of life, developing on the eighth. Keating records a case of a child born with the disease. Steiner has seen it between the second and third weeks.

The pathology of the disease is unsettled, but it appears to be a catarrh of the respiratory organs, combined with an affection of the respiratory nerves, rather than a pure neurosis. This unsettled pathology has led to the employment of remedies without

1 Read before the Medical Society of the District of Columbia, December 8, 886 . 
number. Among them may be mentioned hydrocyanic acid, potassium bromide, ammonium bromide, hyoscyamus, digitalis, alum, lobelia, ipecac, potassium bicarbonate, belladonna, atropine, opium, morphine, musk, sodium et aurum chloride, cocaine, tartar emetic, insufflation and inhalation of quinine. Success and failure have followed the use of each.

In the Medical Record, of July I7, I886, is an editorial on the treatment of whooping-cough, and among the remedies mentioned is narceine. This alkaloid was introduced as a remedy for this disease by Laborde, as far back as 1869 , but the physicians of Philadelphia who employed it about ten years ago failed to obtain the results which were claimed for it. 'The recent visitation of the disease has afforded me a peculiar experience.

It was my intention to thoroughly test this treatment; my reasons for not doing so will be seen from what follows. On July 12, W., born July 3, showed symptoms of whooping-cough, his mother having contracted the disease five days before his birth. He was given on the Igth the following prescription, other remedies having failed to afford relief:

B. Narceine............ o. 133 gm. (gr. ij). Aq. destillat............ 8 c.c. $(3 \mathrm{ij})$

Syr. acaciæ............. 40 c.c. $\left(3^{x}\right)$.

Sig. Teaspoonful every three hours.

This would make the dose .or to gm. (gr. I/6) the minimum, but to insure safety only $1 / 4$ of a teaspoon. ful was given three times a day. Following the second dose there was a decrease in the quantity of urine; the dose was then lessened to 5 drops with the following results:-entire suppression of urine, great drowsiness, refusal to nurse, constipated condition of the bowels and great restlessness. The urine not being voided from 4 in the evening till 6 in the following evening, he was given .oo $6 \mathrm{gm}$. $\left(\frac{1}{4} \overline{0}\right)$ podophyllin every three hours until the bowels were freely moved; 5 drops of spirits of nitre every two hours, and hot poultices to encircle the entire abdomen. This continued until i $2: 30$, when the bowels were acted upon freely and the urine voided; at 8 he again passed urine; the nitre was then continued at four-hour intervals. The whooping-cough was not benefited in the least. Possibly, had the narceine been continued, the effect might have been different, but with such a state of affairs as here presented I could not have the hardihood to do anything which would tend to increase the unfavorable outlook.

This is one experience with narceine. The dose may have been too large, $.0025 \mathrm{gm}$. (gr. $\frac{1}{2} \frac{1}{4}$ ), if so, the condition should have altered when it was lessened. I have no intention of doubting the results obtained by other observers, nor of questioning the reports made concerning the use of "Narceine in Whooping-cough," but I cannot refrain from making known the unfavorable result which followed at my hands. After the effects of the narceine wore away, the child did as well as one so young could be expected upon alum and syrup of wild ginger, to finally have violent convulsions and die on August 2.

510 E. St. N. W., Dec. 8, 1886.

\section{HOSPITAL REPORTS.}

\author{
MYOFIBROMA UTERI.
}

CLINIC OF PROF. ROKITANSKY, OF VIENNA.

[Reported by Horatro R. Bigelow, M.D.]

G. H., 48 years old, married fourteen years. For over one year has had the menses every fortnight, but not very abundantly. Has had four difficult labors, the last one ten years ago. Three weeks ago had a strong hæmorrhage. On the right side of the abdomen there is an ulcer. She is anæmic, small and thin. The lower half of the abdomen is vaulted out by a solid, elastic, circumscribed, movable tumor, not pairful, the walls of which are flat and extending out of the pelvis. Vagina of normal length. The vaginal portion of the uterus is long and broad. The anterior lip is thickened. The posterior lip is flat and thin. Bi-lateral cervical laceration. The interior surface of the anterior lip is soft and swollen; bleeds easily. Through the anterior vaginal roof the enlarged fundus can be detected easily. Circumference around abdomen, four fingers width under navel, $80 \mathrm{ctm}$.; uterus $27 \mathrm{ctm}$.

On account of violent hæmorrhage she was at once received into the hospital, but was soon after discharged, as the bleeding stopped and as she did not wish to be operated upon. On November I 8 , I885, the patient returned to the hospital. After she left the hospital the hæmorrhage returned, and was profuse for five days. Since this time the patient complains of violent pains throughout the abdomen. Examination per vaginam shows a soft, cedematous vaginal portion, and the tumor is more painful than formerly. The bladder is distorted toward the right side, and has a peculiar form. On the right side the probe passes easily up in a vertical direction over the anterior superior oss. il. to a level with the navel; on the left side the probe was only about $3 \mathrm{ctm}$. over the sym. pubes, and through the uterine walls could be felt in the linea alba. On November 21 the patient complained of violent pains in the right side. There was a painful spot over the ninth and tenth ribs, but she had no other signs of pleuritis.

On November 23 the pains ceased entirely, but the patient was unable to lie on the right side. Early on this morning the patient took a hip bath, then the mons veneris was shaved, and the patient had another bath. The abdominal parietes were covered with a linen cloth, moistened in a two per cent. carbolic solution, which was left in situ 20 hours. Temperature $37^{\circ}(\mathrm{R})$, pulse 100 .

On November 20 temp. $37^{\circ}$, pulse 105 . Carbolized sitz bath.

Operation.-Chloroform. The primary incision, made with great care to avoid wounding the bladder, extended from the navel to within 3-4 ctm. of the sym. pubes. Parietal adipose $2 \mathrm{ctm}$. thick. Arteries caught with forceps. When the tumor was disclosed it was found to be smooth, and not adherent to the anterior uterine wall. The incision was found to be too short for its enucleation, so it was extended to a total length of $25 \mathrm{ctm}$. In the peritoneum was a 